This item was submitted to Loughborough's Research Repository by the author.

Items in Figshare are protected by copyright, with all rights reserved, unless otherwise indicated.

\title{
Long working hours and physical activity
}

PLEASE CITE THE PUBLISHED VERSION

http://dx.doi.org/10.1136/jech-2014-205230

PUBLISHER

(c) BMJ Publishing Group

VERSION

AM (Accepted Manuscript)

\section{PUBLISHER STATEMENT}

This work is made available according to the conditions of the Creative Commons Attribution-NonCommercialNoDerivatives 4.0 International (CC BY-NC-ND 4.0) licence. Full details of this licence are available at: https://creativecommons.org/licenses/by-nc-nd/4.0/

\section{LICENCE}

CC BY-NC-ND 4.0

\section{REPOSITORY RECORD}

Angrave, David, Andy Charlwood, and Mark Wooden. 2019. "Long Working Hours and Physical Activity". figshare. https://hdl.handle.net/2134/16957. 


\section{Long Work Hours and Physical Activity}

David Angrave, ${ }^{1}$ Andy Charlwood, ${ }^{2}$ Mark Wooden ${ }^{3}$

${ }^{1}$ The York Management School, University of York, York, UK.

${ }^{2}$ School of Business and Economics, Loughborough University, Loughborough, UK.

${ }^{3}$ Melbourne Institute of Applied Economic and Social Research, University of Melbourne, Melbourne, Australia.

\section{Correspondence to:}

Professor Mark Wooden, Melbourne Institute of Applied Economic and Social Research (Level 6, FBE Bldg, 111 Barry St), University of Melbourne, Victoria, 3010 Australia; m.wooden@unimelb.edu.au

Keywords: employment; hours; longitudinal studies; physical activity; workload

Word count (main text): 2971 


\section{ABSTRACT}

Background. It is widely believed that persons employed in jobs demanding long working hours are at greater risk of physical inactivity than other workers, primarily because they have less leisure time available to undertake such activity. The aim of this study was to test this hypothesis using prospective data obtained from a nationally representative sample of employed persons.

Methods. Longitudinal data from the Household, Income and Labour Dynamics in Australia Survey (93367 observations from 17893 individuals) were used to estimate conditional fixed effects logistic regression models of the likelihood of moderate or vigorous physical exercise for at least 30 minutes at least 4 times are week.

Results. No significant associations between long working hours and the incidence of healthy levels of physical activity were uncovered once other exogenous influences on activity levels were controlled for. The odds of men or women who usually work 60 or more hours per week exercising at healthy levels were $6 \%$ and $11 \%$ less, respectively, than those of comparable persons working a more standard 35 to 40 hour week, but neither estimate was significantly different from zero at the 95\% confidence level.

Conclusions. The findings suggest that there is no trade-off between long working hours and physical activity in Australia. It is argued that these findings are broadly consistent with previous research studies from Anglo-Saxon countries (where long work hours are pervasive) that employed large nationally representative samples. 


\section{INTRODUCTION}

Marked changes in both technology and in the way work is organised have been linked to a rise in obesogenic behaviours, including both increased sedentariness in the workplace and reductions in leisure time spent in physical activity. ${ }^{1}$ One possible contributing factor here is long work hours, something that is characteristic of labour markets in Anglo-Saxon countries. For example, in the UK the Office of National Statistics reports that $19.7 \%$ of all employed persons in 2013 usually worked more than 45 hours per week. ${ }^{2}$ While in Australia, estimates from the monthly Labour Force Survey reveal that, on average, $15.4 \%$ of employed persons in 2013 usually worked 50 hours or more per week. ${ }^{3}$

Previous research has often reported significant negative associations between working hours and the incidence of regular physical activity, ${ }^{4-11}$ with one review concluding that there is "convincing evidence" to support the "premise that those employed in occupations demanding long work hours ... are at risk of inactivity”. ${ }^{1}$ Our own reading of the evidence is rather different. First, the evidence is more mixed than suggested by this review, with a number of studies unable to detect any significant negative associations. ${ }^{12-15}$ Second, within the body of supportive evidence, relationships are often small, ${ }^{4,5,7}$ only significant for certain sub-groups, such as men ${ }^{4,6,9,11}$ or white-collar workers, ${ }^{5}$ and sometimes driven by differences between full-time workers and part-time workers, rather than by working hours patterns that could be regarded as unreasonable or excessive. ${ }^{4,10}$ A serious weakness of much of the literature is the predominance of cross-sectional data. Only two relevant prior studies have employed prospective data, and one of those only had observations at two points in time, ${ }^{12}$ while the other employed a random effects model, which will deliver biased results if the individual-specific error component is correlated with other covariates. ${ }^{10}$

To overcome these weaknesses, we re-examined the association between physical activity and working time using data that were both representative of a national population of workers 
and prospective. The key feature of the analysis is the estimation of conditional fixed effects logistic regression models where the estimated parameters are identified by within-person differences. In this approach, all time-invariant influences on the outcome variable were held constant and thus the likelihood of omitted variables bias much reduced. Our study also included more detailed measures of working time and a broader measure of physical activity than previous studies.

\section{METHODS}

\section{Data and sample}

The data used in this analysis were participants in waves 1 to 12 of the Household, Income and Labour Dynamics in Australia (HILDA) Survey, a longitudinal survey following members of a nationally representative sample of Australian households. ${ }^{16,17}$ Funded by the Australian Government but managed by the Melbourne Institute of Applied Economic and Social Research, all data collection protocols and materials used in the HILDA Survey have been approved by the University of Melbourne Human Research Ethics Committee and verified as consistent with the National Statement on Ethical Conduct in Human Research. ${ }^{18}$

It commenced in 2001 with an initial responding sample of 13969 persons, aged 15 years or older, from 7682 households. Further interviews were sought every subsequent year with all of these persons, along with any other adult household members. Annual re-interview rates were high, rising from $87 \%$ in wave 2 to over $94 \%$ by wave 5 (and remaining above that level ever since).

While the principal mode of data collection was personal interview, the information about physical activity came from a self-administered questionnaire, which was often collected from interview respondents at a later date, and hence associated with additional non- 
response; on average, about $90 \%$ of interviewees completed and returned the selfadministered questionnaire each year. The sample was restricted to persons in paid employment during the week prior to interview. The final sample used in the analysis comprised 93367 observations from 17893 individuals.

\section{Measures}

The outcome of interest, the frequency of physical exercise, is derived from answers to the question: "In general, how often do you participate in moderate or intensive physical activity for at least 30 minutes?” Moderate level activity is defined within the survey instrument as activity that "will cause a slight increase in breathing and heart rate”, with "brisk walking” provided as an example. Six pre-coded response categories are provided: “Not at all”, "Less than once a week", “One to two times a week”, “Three times a week”, “More than 3 times a week (but not every day)”, and "Every day”. While providing only a crude measure of physical activity, the use of similar single-item questions is very prevalent in this literature. , $6,8-10,12-13^{-13}$

The unweighted distribution of responses within the pooled sample of employed persons, disaggregated by sex, is reported in Table 1 . While comparisons with other (cross-sectional) sources are complicated by differences in definitions and measurement, it has been reported that the levels of physical activity recorded in the HILDA Survey are comparable to that recorded in other Australian samples. ${ }^{19}$

In the analyses reported here, a binary variable was constructed that distinguishes those that exercise more than three times a week from those that exercise less frequently. The implicit assumption is that exercising for at least 30 minutes on at least four occasions during a week represents a healthy level of exercise. This choice of cut-off is close to the minimum 
recommended by the American College of Sports Medicine and the American Heart Association: 30 minutes of at least moderate exercise on 5 days a week. ${ }^{20}$ It has also been used in other research (examining the impact of physical exercise on life satisfaction) utilising the HILDA Survey data. ${ }^{21}$

The main explanatory variable of interest is usual hours of work per week in paid employment, in all jobs, and including any paid or unpaid overtime. If a respondent indicated that their hours of work varied, they were asked to estimate the number of hours typically worked over a 4-week period, which was then averaged. The distribution of hours worked, within bands, is provided in Table 1 . As can be seen, a sizeable proportion of the sample reported usually working in excess of 50 hours per week (27\% of male workers and $8 \%$ of female workers). This is broadly consistent with official estimates from the Australian Labour Force Survey over the period covered by these data. ${ }^{22}$

Previous research suggests that other job characteristics may also influence physical activity levels. It has, for example, been hypothesised that features of work associated with employment status or specific occupations may help explain variations across individuals in exercise time. ${ }^{1}$ We might also expect negative associations with shift work given other evidence demonstrating negative associations between shift work and the quality and quantity of sleep. ${ }^{23}$ We thus included dummy variables identifying shift workers, the self-employed, and eight broad occupation groups.

Finally, a large range of other controls were included that might be expected to influence physical activity levels. These were: age (dummy variables defining 10-year age bands); marital status; the number of dependent children within two separate age categories $(<5$ years and 5-18 years); highest level of education attainment (two dummies identifying obtaining a university-level qualification and completing high school); the presence of a long-term health condition or disability that is work limiting; self-rated health (four dummies defining five 
different health states); whether any other household member regularly exercised at least 4 times per week; usual weekly hours of commuting; real disposable household income, adjusted for household size and composition using the OECD modified equivalence scale ${ }^{24}$ (with missing values imputed ${ }^{25}$ ); whether residing in a major Australian city; the level of relative socio-economic deprivation of the local area (two dummies, identifying high and medium deprivation areas, derived from the Index of Relative Socio-economic Advantage / Disadvantage constructed by the Australian Bureau of Statistics ${ }^{26}$ ); and year dummies.

\section{Estimation methods}

Given a binary outcome variable, logistic regression methods were employed. Three types of logistic models were estimated: (i) simple models using the pooled data set (but which allowed for the clustering of observations within individuals); (ii) panel data models assuming an individual-specific random disturbance (random effects); and (iii) panel data models assuming an individual-specific constant (conditional fixed effects). ${ }^{27}$ The latter two models are designed to both account for the interdependence of observations given the repeated measurement of individuals, and control for unobserved heterogeneity. The random effects model assumes the individual-specific effects are independent of the set of explanatory variables (i.e., that time-invariant personality traits and genetic characteristics do not influence choice of occupation, working time, etc.), whereas the fixed effects model makes no such assumption. Ex ante, we strongly preferred the conditional fixed effects specification given it holds constant all time-invariant influences on the outcome variable; but whether it is the more appropriate estimator was tested formally through the use of a Hausman test. ${ }^{28}$ Note the use of fixed effects implies a decline in effective sample size given that only observations where the outcome variable changes from the preceding period are used. 
Men and women are expected to face different time constraints, ${ }^{19}$ and hence separate models were estimated for men and women. All analyses were undertaken using the Stata (Release 13) software package.

\section{RESULTS}

Selected estimates (odds ratios plus 95\% confidence intervals) from logistic regression models of exercising at 'healthy' levels (i.e., at least four times are week) are presented in Table 2. The parameters of most interest are those on the hours of work dummies. Focussing first on males, the simple 'unadjusted' logit results, where the sample is pooled and effectively treated as a cross-section and where no control variables are included (column 1), suggests an inverse relationship between hours of work and physical activity. The likelihood of exercising at healthy frequency levels is greatest for men who work part-time hours and lowest for those working quite long hours each week (between 50 and 59). Once we include controls for other individual and job characteristics, however, this relationship disappears (column 2). In the presence of other controls there are no significant differences in the likelihood of healthy exercise between male workers on a (standard) 35 to 40 hour week (the reference group) and those working different hours (either more or less). Moving to a random effects specification saw a large increase in the pseudo R-squared statistic, reflecting the importance of unobserved individual effects. Nevertheless, the estimated odds ratios on the different hours of work dummies were little affected. Results from a fixed effects specification are presented in column 4. The pseudo R-squared is even larger, but more importantly, a large value on the Hausman test $\left(\chi^{2}=286.7\right)$ indicated that the assumption that the covariates are uncorrelated with the individual-specific effects should be rejected, and hence the fixed effects estimates were preferred. In these results, there is some evidence that it is actually men who usually work hours longer than the standard 35 to 40 hour work week 
who are the most physically active; those in the 41 to 49 hour a week range. For men who work more hours than this the likelihood of healthy activity levels declines, but the difference between them and otherwise comparable men working a 35 to 40 hour week is still not statistically significant.

Turning to female workers, estimates from the same four specifications are presented. Test statistics both strongly augured for the presence of individual-specific effects and favoured the fixed effects specification over random effects. In this case, however, there was no evidence (in any of the specifications) that long-hours workers were any less likely to engage in healthy levels of physical exercise than those working a more conventional 35 to 40 hour week. Indeed, it was women who worked part-time hours, and more specifically 21 to 34 hours each week, who were the least likely to exercise at healthy levels.

Of the other job characteristics reported in Table 2, we can see that self-employment is consistently associated with a higher likelihood of frequent physical activity. This most likely reflects the greater autonomy and discretion the self-employed have over their working time. As expected, shift work is negatively associated with physical activity frequency, but the differences with other workers are only statistically significant for women. Finally, the patterns in the estimated odds ratios on the occupation dummies indicate higher levels of physical activity, all other things equal, among workers in blue-collar dominated occupations. In part, this reflects the use of an activity measure that is not restricted to physical activity that only occurs during leisure time, and in part the possibility that workers who are more physically active at work are also more physically active during leisure. Certainly previous research has more often than not reported that occupation physical activity and leisure time physical activity are positively correlated. ${ }^{1}$

We next tested whether our results are sensitive to the way we specify hours of work. We thus re-estimated each of our four models after replacing the hours dummies with: (i) a 
continuous hours variable; (ii) a quadratic hours function; and (iii) the natural log of hours. This gives us 12 different model specifications. The estimated odds ratios for the key hours variable(s) from each of these 12 specifications, again for both men and women, are reported in Table 3. In virtually all cases, the parameter estimates are not significantly different from zero once controls for other covariates are included.

Finally, like all studies that use longitudinal data, it is possible that the results are affected by selective attrition. Following previous research using these data, ${ }^{19,29}$ we tested for this by repeating the estimations after including an additional variable indicating whether the individual responded at the next survey wave. If attrition bias is not present then there should be no significant association between the outcome at time $t$ and survey participation at $t+1$. In all models the null hypothesis of random non-response could not be rejected.

\section{DISCUSSION}

The results of the analyses presented here challenge the conventional wisdom that persons who regularly work long hours are necessarily at greater risk of low levels of physical activity. Using nationally representative longitudinal survey data from Australia, we could find little evidence of statistically important associations between physical activity levels and the length of the usual work week once other individual and job characteristics were controlled for. Indeed, among men there was some evidence that the likelihood of exercising 4 times a week or more was highest among those working between 41 and 49 hours per week, and hence longer than a standard length work week.

Such findings may seem counter-intuitive given that at some point there must be a tradeoff between time spent on one activity (e.g., paid work) and the time spent on another (e.g., physical exercise). However, in the case of the physical activity measure employed here, the 
minimum time requirement is just two hours per week. This leaves ample scope for increases in working time to be accommodated by reductions in other activity, such as more sedentary leisure activity, rather than through reductions in physical activity.

Also, despite claims to the contrary, ${ }^{1}$ the results presented are broadly consistent with other findings from studies using relatively large samples of employed persons in other predominantly Anglo-Saxon countries (Australia, Canada, the UK, and the US), which have reported either no significant associations, ${ }^{12-13}$ or at least no significant differences between the physical activity levels of long hours workers and that of other full-time workers. ${ }^{4,10}$ It is thus possible that differences across countries in work cultures and in the acceptance of long working hours regimes may help explain differences across studies.

This study also found evidence that women who worked 21 to 34 hours a week were less likely to exercise 4 times a week or more. This result appears to contradict previous research based on the same data source, ${ }^{19}$ which we believe may be due to the more detailed measures of hours and other job characteristics used in this study. We can only speculate as to the reasons for this significant negative coefficient. It may be that women who work part-time are more sensitive to time constraints imposed by changes to working time because of the need to balance paid and unpaid work within a rigid household division of labour. Many women who enter the 21 to 34 hours category are increasing their hours, so may find the time available to exercise constrained by the increase in work time. Among those reducing their hours, there may be parallel and unobserved change in life circumstances (for example, increased caring responsibilities) which reduces the time available for both work and exercise.

One possibly important difference with this study and some previous studies is the use of an outcome measure that includes all forms of physical activity, rather than one restricted to physical activity that occurs during leisure time. The outcome used here thus includes 
physical activity that occurs as a by-product of work. This is controlled for, in part, through the inclusion of occupation-specific dummy variables. Nevertheless, it remains the case that some of the variation in the outcome variable will be driven by changes in activity levels within the workplace. Another limitation is the crude nature of the outcome measure. It only provides a count of the number of days each week people exercise for at least 30 minutes, and even then answers are banded.

Against these limitations must be set the strength of longitudinal data that is nationally representative. The overwhelming majority of studies into the relationship between work and physical activity are based on cross-sectional data. In this context, the differences in results between our pooled cross-sectional models and our fixed effects models are instructive. In the light of our results, it seems likely that studies based on cross-sectional data will mislead, with results biased by omitted variables (time invariant aspects of genetic and personality traits) correlated with observed characteristics. Fixed effects specifications are necessary to adequately control for these characteristics. In future, researchers concerned with the relationship between work and health risk behaviours should focus their efforts on prospective research designs.

\section{What is already known on this subject}

It is widely assumed that persons employed in jobs demanding long work hours are at greater risk of physical inactivity than other workers. The evidence in support of such claims, however, is far from convincing. A particular weakness is that most prior research has employed cross-sectional data sources, and thus not been able to adequately control for the many unobserved factors that influence activity levels. 


\section{What this study adds}

This study is one of only three that has employed longitudinal data drawn from a nationally representative sample to examine the association between working time (and especially long work hours regimes) and physical activity levels, and the first to utilise methods that adequately control for (time-invariant) individual-specific characteristics and traits. Little supporting evidence could be found for the claim that average physical activity levels are adversely affected by the time demands of employment.

\section{Acknowledgements}

The paper uses unit record data from Release 12.0 of the Household, Income and Labour Dynamics in Australia (HILDA) Survey, a project initiated and funded by the Australian Government Department of Social Services and managed by the Melbourne Institute of Applied Economic and Social Research, University of Melbourne.

\section{Competing interests}

None

\section{Ethics approval}

University of Melbourne Human Research Ethics Committee

\section{Data sharing statement}

The unit-record data from the HILDA Survey are available to bona fide researchers under a license provided by the Australian Government. Details of how to apply can be found at: www.melbourneinstitute.com/hilda/data. 


\section{REFERENCES}

1. Kirk MA, Rhodes RE. Occupation correlates of adults’ participation in leisure-time physical activity: a systematic review. Am J Prev Med 2011;40:476-485. doi:10.1016/j.amepre.2010.12.015

2. Office for National Statistics. Labour Market Statistics, June2014. (Excel spreadsheet table. HOUR0: Usual weekly hours worked.) http://www.ons.gov.uk/ons/rel/lms/labourmarket-statistics/june-2014/table-hour02.xls; accessed 10 November 2014.

3. Australian Bureau of Statistics (ABS). Labour Force, Australia, Detailed - Electronic Delivery, Aug. 2014. (ABS cat. no. 6291.0.55.001. Time series spreadsheets: Table 10. Employed persons and usual hours worked by sex.) www.abs.gov.au/AUSSTATS/abs@.nsf/DetailsPage/6291.0.55.001Aug\%202014?Open Document; accessed 1 October 2014.

4. Burton NW, Turrell G. Occupation, hours worked, and leisure-time physical activity. Prev Med 2000;31:673-681. doi:10.1006/pmed.2000.0763

5. Wu B, Porell F. Job characteristics and leisure physical activity. J Aging Health 2000;12:538-559. doi:10.1177/089826430001200405

6. Takao S, Kawakami N, Ohtsu T. Occupational class and physical activity among Japanese employees. Soc Sci Med 2003;57:2281-2289. doi:10.1016/S02779536(03)00134-5

7. Nomaguchi KM, Bianchi SM. Exercise time: gender differences in the effects of marriage, parenthood, and employment. J Marriage Fam 2004;66:413-430. doi:10.1111/j.1741-3737.2004.00029.x 
8. Schneider S, Becker S. Prevalence of physical activity among the working population and correlation with work-related factors: results from the first German National Health Survey. J Occup Health 2005;47:414-423. doi:10.1539/joh.47.414

9. Wemme K, Magnus, Rosvall M. Work related and non-work related stress in relation to low leisure time physical activity in a Swedish population. J Epidemiol Community Health 2005;59:377-379. doi:10.1136/jech.2004.031526

10. Popham F, Mitchell R. Leisure time exercise and personal circumstances in the working age population: longitudinal analysis of the British Household Panel Survey. J Epidemiol Community Health 2006;60:270-274. doi:10.1136/jech.2005.041194

11. Artazcoz L, Cortes I, Escriba-Aguir V, et al. Understanding the relationship of long working hours with health status and health related behaviors. J Epidemiol Community Health 2009;63:521-527. doi:10.1136/jech.2008.082123

12. Shields M. Long working hours and health. Health Rep 1999;11:33-48 (English); 37-55 (French).

13. Grzywacz JG, Marks NF. Social inequalities and exercise during adulthood: towards an ecological perspective. J Health Soc Behav 2001;42:202-220.

14. Lallukka T, Sarlio-Lähteenkorva S, Roos E, et al. Working conditions and health behaviours among employed women and men: the Helsinki health study. Prev Med 2004;38:48-56. doi:10.1016/j.ypmed.2003.09.027

15. Lallukka T, Lahelma E, Rahkonen O, et al. Associations of job strain and working overtime with adverse health behaviours and obesity: evidence from the Whitehall II study, Helsinki health study, and the Japanese civil servants study. Soc Sci Med 2008;66:1681-1698. doi:10.1016/j.socscimed.2007.12.027 
16. Watson N, Wooden M. The HILDA Survey: a case study in the design and development of a successful household panel study. Longit Life Course Stud 2012;3:369-381. doi:10.14301/llcs.v3i3.208

17. Summerfield M, Freidin S, Hahn M, et al. HILDA User Manual-Release 12. Melbourne: Melbourne Institute of Applied Economic and Social Research, University of Melbourne, 2013.

18. The National Health and Medical Research Council, the Australian Research Council and the Australian Vice-Chancellors' Committee. National Statement on Ethical Conduct in Human Research 2007 (updated March 2014). Canberra: Commonwealth of Australia.

19. Brown H, Roberts J. Exercising choice: the economic determinants of physical activity behaviour of an employed population. Soc Sci Med 2011;73:383-390. doi:10.1016/j.socscimed.2011.06.001

20. Haskell WL, Lee I-M, Pate RR, et al. Physical activity and public health: updated recommendation for adults from the American College of Sports Medicine and the American Heart Association. Circulation 2007;116:1081-1093. doi:10.1161/CIRCULATION.107.185649

21. Perales F, del Pozo-Cruz J, del Pozo-Cruz J, del Pojo-Cruz B. On the associations between physical activity and quality of life: findings from an Australian nationally representative panel survey. Qual Life Res 2014;23:1921-1933. doi:10.1007/s11136-0140645-4

22. Wilkins R, Wooden M. Two decades of change: the Australian labour market, 19932013. Aust Econ Rev 2014;47:417-431. doi:10.1111/1467-8462.12085

23. Akerstedt T. Shift work and disturbed sleep/wakefulness. Occup Med-C 2003;53:89-94. doi: 10.1093/occmed/kqg046 
24. Hagenaars A, de Vos K, Zaidi MA. Poverty Statistics in the Late 1980s: Research Based on Micro-data. Luxembourg: Office for Official Publications of the European Communities, 1994.

25. Hayes C, Watson N. HILDA Imputation Methods. Melbourne: Melbourne Institute of Applied Economic and Social Research, University of Melbourne, 2009. HILDA Project Technical Paper Series no. 2/09.

26. Australian Bureau of Statistics (ABS). Census of Population and Housing: SocioEconomic Indexes for Areas (SEIFA), Australia (ABS cat. no. 2033.0.30.001). Canberra: ABS; 2001.

27. Hamerle A, Ronning G. Panel analysis for qualitative variables. In: Arminger G, Clogg CC, Sobel ME, eds. Handbook of Statistical Modelling for the Social and Behavioral Sciences. New York: Plenum; 1995:401-455.

28. Hausman JA. Specification tests in econometrics. Econometrica. 1978;46(6):1251-1371. doi:10.2307/1913827

29. Wooden M, Li N. Panel conditioning and subjective well-being. Soc Indic Res. 2014;117(1):235-255. doi:10.1007/s11205-013-0348-1 
Table 1 Incidence of Physical Activity and Usual Weekly Work Hours among Employed Persons in Australia: HILDA Survey Waves 1 to 12 (\%)

\begin{tabular}{lrrr}
\hline & Males & Females & Persons \\
\hline Frequency of physical activity & & & \\
$\quad$ Not at all & 6.6 & 8.2 & 7.4 \\
Less than once a week & 14.5 & 18.5 & 16.5 \\
One to 2 times a week & 23.8 & 26.2 & 25.0 \\
3 times a week & 15.6 & 17.2 & 16.4 \\
More than 3 times a week & 23.2 & 20.4 & 21.8 \\
Every day & 16.3 & 9.5 & 12.9 \\
Total & 100.0 & 100.0 & 100.0 \\
& & & \\
Usual weekly hours of paid work & & 24.1 & 16.6 \\
Less than 20 & 9.1 & 26.4 & 18.0 \\
$21-34$ & 9.6 & 32.7 & 33.4 \\
35-40 & 36.1 & 8.6 & 13.4 \\
$41-49$ & 18.1 & 5.6 & 11.1 \\
50-59 & 16.6 & 2.7 & 6.5 \\
$60+$ & 10.6 & 100.0 & 100.0 \\
Total & 100.0 & & \\
\hline
\end{tabular}


Table 2 Associations between Job Characteristics and Exercising 4 or More Times a Week: Odds Ratios

\begin{tabular}{|c|c|c|c|c|c|c|c|c|}
\hline & \multicolumn{4}{|c|}{ Males } & \multicolumn{4}{|c|}{ Females } \\
\hline & $\begin{array}{l}\text { Pooled (no } \\
\text { controls) } \\
(1)\end{array}$ & $\begin{array}{l}\text { Pooled (with } \\
\text { controls) } \\
\text { (2) }\end{array}$ & $\begin{array}{l}\text { Random } \\
\text { effects } \\
\text { (3) }\end{array}$ & $\begin{array}{l}\text { Fixed } \\
\text { effects } \\
(4)\end{array}$ & $\begin{array}{l}\text { Pooled (no } \\
\text { controls) } \\
(5)\end{array}$ & $\begin{array}{l}\text { Pooled (with } \\
\text { controls) } \\
(6)\end{array}$ & $\begin{array}{c}\text { Random } \\
\text { effects } \\
\text { (7) }\end{array}$ & $\begin{array}{l}\text { Fixed } \\
\text { effects } \\
(8)\end{array}$ \\
\hline \multicolumn{9}{|l|}{$\begin{array}{l}\text { Usual weekly hours of paid } \\
\text { work }\end{array}$} \\
\hline Less than 20 & $\begin{array}{c}1.36 * * \\
(1.24,1.49)\end{array}$ & $\begin{array}{c}1.00 \\
(0.89,1.12)\end{array}$ & $\begin{array}{c}1.00 \\
(0.88,1.14)\end{array}$ & $\begin{array}{c}1.05 \\
(0.90,1.22)\end{array}$ & $\begin{array}{c}0.95 \\
(0.88,1.03)\end{array}$ & $\begin{array}{c}0.99 \\
(0.90,1.09)\end{array}$ & $\begin{array}{c}0.93 \\
(0.84,1.04)\end{array}$ & $\begin{array}{c}0.94 \\
(0.83,1.06)\end{array}$ \\
\hline $21-34$ & $\begin{array}{c}1.20 * * \\
(1.10,1.31)\end{array}$ & $\begin{array}{c}1.07 \\
(0.97,1.18)\end{array}$ & $\begin{array}{c}1.06 \\
(0.95,1.18)\end{array}$ & $\begin{array}{c}1.06 \\
(0.94,1.19)\end{array}$ & $\begin{array}{c}0.91^{*} \\
(0.85,0.99)\end{array}$ & $\begin{array}{c}0.96 \\
(0.88,1.04)\end{array}$ & $\begin{array}{c}0.88^{* *} \\
(0.80,0.96)\end{array}$ & $\begin{array}{c}0.88^{*} \\
(0.79,0.97)\end{array}$ \\
\hline $35-40$ & $\begin{array}{c}1 \\
\text { (Ref. cat.) }\end{array}$ & $\begin{array}{c}1 \\
\text { (Ref. cat.) }\end{array}$ & $\begin{array}{c}1 \\
\text { (Ref. cat.) }\end{array}$ & $\begin{array}{c}1 \\
\text { (Ref. cat.) }\end{array}$ & $\begin{array}{c}1 \\
\text { (Ref. cat.) }\end{array}$ & $\begin{array}{c}1 \\
\text { (Ref. cat.) }\end{array}$ & $\begin{array}{c}1 \\
\text { (Ref. cat.) }\end{array}$ & $\begin{array}{c}1 \\
\text { (Ref. cat.) }\end{array}$ \\
\hline $41-49$ & $\begin{array}{c}0.95 \\
(0.89,1.02)\end{array}$ & $\begin{array}{c}1.00 \\
(0.93,1.08)\end{array}$ & $\begin{array}{c}1.08 \\
(1.00,1.18)\end{array}$ & $\begin{array}{c}1.12 * \\
(1.02,1.23)\end{array}$ & $\begin{array}{c}1.04 \\
(0.94,1.14)\end{array}$ & $\begin{array}{c}1.01 \\
(0.92,1.11)\end{array}$ & $\begin{array}{c}1.00 \\
(0.89,1.13)\end{array}$ & $\begin{array}{c}1.00 \\
(0.88,1.13)\end{array}$ \\
\hline $50-59$ & $\begin{array}{c}0.86 * * \\
(0.80,0.93)\end{array}$ & $\begin{array}{c}0.94 \\
(0.86,1.02)\end{array}$ & $\begin{array}{c}0.94 \\
(0.85,1.03)\end{array}$ & $\begin{array}{c}0.95 \\
(0.86,1.05)\end{array}$ & $\begin{array}{c}1.03 \\
(0.90,1.17)\end{array}$ & $\begin{array}{c}0.92 \\
(0.80,1.06)\end{array}$ & $\begin{array}{c}0.99 \\
(0.85,1.15)\end{array}$ & $\begin{array}{c}1.05 \\
(0.89,1.24)\end{array}$ \\
\hline $60+$ & $\begin{array}{c}0.99 \\
(0.90,1.10)\end{array}$ & $\begin{array}{c}1.03 \\
(0.93,1.15)\end{array}$ & $\begin{array}{c}0.99 \\
(0.88,1.11)\end{array}$ & $\begin{array}{c}0.93 \\
(0.81,1.06)\end{array}$ & $\begin{array}{c}1.05 \\
(0.86,1.28)\end{array}$ & $\begin{array}{c}0.93 \\
(0.76,1.15)\end{array}$ & $\begin{array}{c}0.89 \\
(0.72,1.11)\end{array}$ & $\begin{array}{c}0.89 \\
(0.69,1.14)\end{array}$ \\
\hline Self-employed & & $\begin{array}{c}1.17 * * \\
(1.06,1.28)\end{array}$ & $\begin{array}{c}1.24^{* *} \\
(1.12,1.36)\end{array}$ & $\begin{array}{c}1.14^{*} \\
(1.00,1.30)\end{array}$ & & $\begin{array}{c}1.33^{* *} \\
(1.18,1.50)\end{array}$ & $\begin{array}{c}1.56 * * \\
(1.37,1.79)\end{array}$ & $\begin{array}{c}1.54^{* *} \\
(1.29,1.84)\end{array}$ \\
\hline Shift worker & & $\begin{array}{c}0.97 \\
(0.91,1.05)\end{array}$ & $\begin{array}{c}0.97 \\
(0.90,1.05)\end{array}$ & $\begin{array}{c}0.98 \\
(0.90,1.06)\end{array}$ & & $\begin{array}{c}0.95 \\
(0.88,1.02)\end{array}$ & $\begin{array}{c}0.90 * * \\
(0.83,0.97)\end{array}$ & $\begin{array}{c}0.86^{* *} \\
(0.78,0.94)\end{array}$ \\
\hline \multicolumn{9}{|l|}{ Occupation } \\
\hline Managers & & $\begin{array}{c}1 \\
\text { (Ref. cat.) }\end{array}$ & $\begin{array}{c}1 \\
\text { (Ref. cat.) }\end{array}$ & $\begin{array}{c}1 \\
\text { (Ref. cat.) }\end{array}$ & & $\begin{array}{c}1 \\
\text { (Ref. cat.) }\end{array}$ & $\begin{array}{c}1 \\
\text { (Ref. cat.) }\end{array}$ & $\begin{array}{c}1 \\
\text { (Ref. cat.) }\end{array}$ \\
\hline Professionals & & $\begin{array}{c}0.99 \\
(0.90,1.11)\end{array}$ & $\begin{array}{c}1.09 \\
(0.97,1.22)\end{array}$ & $\begin{array}{c}1.16 \\
(1.01,1.32)\end{array}$ & & $\begin{array}{c}0.98 \\
(0.86,1.12)\end{array}$ & $\begin{array}{c}1.03 \\
(0.90,1.19)\end{array}$ & $\begin{array}{c}1.06 \\
(0.90,1.26)\end{array}$ \\
\hline $\begin{array}{l}\text { Technicians and trades } \\
\text { workers }\end{array}$ & & $1.36^{* *}$ & $1.42 * *$ & $1.22^{* *}$ & & $1.23 *$ & $1.35^{* *}$ & $1.37 *$ \\
\hline & & $(1.22,1.51)$ & $(1.27,1.60)$ & $(1.06,1.41)$ & & $(1.02,1.47)$ & $(1.09,1.66)$ & $(1.07,1.74)$ \\
\hline
\end{tabular}


Community and personal service workers

Clerical and

administrative workers

Sales workers

Machinery operators and

drivers

Labourers

$\mathrm{N}$ (observations)

$\mathrm{N}$ (individuals)

Likelihood ratio (chisquared)

Pseudo R-squared

Hausman test (chi-squared)

$\begin{array}{ccc}1.34 * * & 1.37 * * & 1.21 \\ (1.15,1.56) & (1.16,1.62) & (0.99,1.48) \\ 1.00 & 1.08 & 1.14 \\ (0.87,1.14) & (0.94,1.25) & (0.97,1.34) \\ 0.97 & 1.13 & 1.23^{*} \\ (0.84,1.12) & (0.97,1.32) & (1.03,1.46) \\ 1.40^{* *} & 1.45^{* *} & 1.16 \\ & & \\ (1.24,1.60) & (1.26,1.67) & (0.98,1.38) \\ 1.79 * * & 1.92 * * & 1.55^{* *} \\ (1.59,2.02) & (1.69,2.19) & (1.33,1.80)\end{array}$

48,297
9,032

$186.26^{* * *}$
45,384

9,032

3316.49**

0.05

45,384 29,321

$9,032 \quad 3,878$

0.01
1577.51** 691.37**

0.41

0.54
$1.31^{* *}$
$(1.14,1.51)$
1.02
$(0.90,1.16)$
1.00
$(0.86,1.15)$
1.28

$1.36 * *$

$1.23^{*}$

$(1.16,1.60) \quad(1.02,1.48)$

1.07

1.10

$(0.93,1.24) \quad(0.93,1.30)$

1.08

1.14

(0.95,1.38)

$1.72 * *$

$1.60 *$

$(0.97,1.70)$
$1.68 * *$

$(1.23,2.39)$

$1.63 * *$

(1.10,2.33)

$1.27 *$

(1.43,1.98)

(1.36,1.95)

(1.02,1.58)

\section{2,610}

8,861

42,610

8,861

24,284

8,861

$191.17 * *$

2503.11**

$1149.52 * *$

$588.03 * *$

0.00

0.05

0.48
0.40

$164.4^{* *}$

Notes. 95\% confidence intervals are presented in parentheses. ${ }^{* *} \mathrm{p}<0.01,{ }^{*} \mathrm{p}<0.05$.

Models 2 through 4 and 6 through 8 also controlled for: the presence of another household member who exercised four or more times a week; age; marital status; number of children (by age of child); real disposable equivalized household income; educational level; disability, self-rated health; commuting hours; residence in a major city; relative socio-economic deprivation of the local area; and year. 
Table 3 Associations between Usual Hours of Work and Exercising 4 or More Times a Week (Odds Ratios): Alternative Specifications

\begin{tabular}{|c|c|c|c|c|c|c|}
\hline \multirow[b]{2}{*}{$\begin{array}{l}\text { Sample / } \\
\text { Model }\end{array}$} & \multirow{2}{*}{$\begin{array}{c}\text { (I) } \\
\text { Usual weekly } \\
\text { hours of paid } \\
\text { work }\end{array}$} & \multicolumn{2}{|c|}{ (II) } & \multirow{2}{*}{$\begin{array}{c}\text { (III) } \\
\text { Ln usual weekly } \\
\text { hours of paid } \\
\text { work }\end{array}$} & \multirow[b]{2}{*}{$\begin{array}{c}\mathrm{N} \\
\text { (observations) }\end{array}$} & \multirow[b]{2}{*}{$\begin{array}{c}\mathbf{N} \\
\text { (individuals) }\end{array}$} \\
\hline & & $\begin{array}{c}\text { Usual weekly } \\
\text { hours of paid } \\
\text { work }\end{array}$ & $\begin{array}{l}\text { Usual weekly } \\
\text { hours of paid } \\
\text { work squared }\end{array}$ & & & \\
\hline \multicolumn{7}{|l|}{ Males } \\
\hline Pooled (no controls) & $\begin{array}{c}0.99 * * * \\
(0.99,1.00)\end{array}$ & $\begin{array}{c}0.98 * * * \\
(0.97,0.98)\end{array}$ & $\begin{array}{c}1.00 * * * \\
(1.00,1.00)\end{array}$ & $\begin{array}{c}0.82 * * * \\
(0.78,0.86)\end{array}$ & 48,297 & 9,032 \\
\hline Pooled (with controls) & $\begin{array}{c}1.00 \\
(1.00,1.00)\end{array}$ & $\begin{array}{c}0.99 \\
(0.99,1.00)\end{array}$ & $\begin{array}{c}1.00 * \\
(1.00,1.00)\end{array}$ & $\begin{array}{c}1.02 \\
(0.96,1.08)\end{array}$ & 45,384 & 9,032 \\
\hline Random effects & $\begin{array}{c}1.00 \\
(1.00,1.00)\end{array}$ & $\begin{array}{c}1.00 \\
(0.99,1.00)\end{array}$ & $\begin{array}{c}1.00 \\
(1.00,1.00)\end{array}$ & $\begin{array}{c}1.00 \\
(0.94,1.08)\end{array}$ & 45,384 & 9,032 \\
\hline Fixed effects & $\begin{array}{c}1.00 \\
(1.00,1.00)\end{array}$ & $\begin{array}{c}0.99 \\
(0.99,1.00)\end{array}$ & $\begin{array}{c}1.00 \\
(1.00,1.00)\end{array}$ & $\begin{array}{c}0.95 \\
(0.87,1.04)\end{array}$ & 29,332 & 3,879 \\
\hline \multicolumn{7}{|l|}{ Females } \\
\hline Pooled (no controls) & $\begin{array}{c}1.00 * \\
(1.00,1.00)\end{array}$ & $\begin{array}{c}1.00 \\
(0.99,1.00)\end{array}$ & $\begin{array}{c}1.00 * \\
(1.00,1.00)\end{array}$ & $\begin{array}{c}1.03 \\
(0.98,1.08)\end{array}$ & 45,070 & 8,861 \\
\hline Pooled (with controls) & $\begin{array}{c}1.00 \\
(1.00,1.00)\end{array}$ & $\begin{array}{c}1.00 \\
(0.99,1.00)\end{array}$ & $\begin{array}{c}1.00 \\
(1.00,1.00)\end{array}$ & $\begin{array}{c}0.99 \\
(0.94,1.05)\end{array}$ & 42,610 & 8,861 \\
\hline Random effects & $\begin{array}{c}1.00 \\
(1.00,1.00)\end{array}$ & $\begin{array}{c}1.00 \\
(0.99,1.01)\end{array}$ & $\begin{array}{c}1.00 \\
(1.00,1.00)\end{array}$ & $\begin{array}{c}1.00 \\
(0.94,1.06)\end{array}$ & 42,610 & 8,861 \\
\hline Fixed effects & $\begin{array}{c}1.00 \\
(1.00,1.00)\end{array}$ & $\begin{array}{c}1.00 \\
(0.99,1.01)\end{array}$ & $\begin{array}{c}1.00 \\
(1.00,1.00)\end{array}$ & $\begin{array}{c}0.99 \\
(0.92,1.07)\end{array}$ & 24,296 & 3,319 \\
\hline
\end{tabular}

Notes. 95\% confidence intervals are presented in parentheses. ** $\mathrm{p}<0.01,{ }^{*} \mathrm{p}<0.05$.

All models also controlled for: self-employment; shift work; occupation; the presence of another household member who exercised four or more times a week; age; marital status; number of children (by age of child); real disposable equivalized household income; educational level; disability, self-rated health; commuting hours; residence in a major city; relative socio-economic deprivation of the local area; and year. 